\title{
ENHANCING MOTIVATION, ENGAGEMENT AND TEAM BUILDING AMONG PSYCHOLOGY UNDERGRADUATES THROUGH GAME BASE LEARNING
}

\author{
P. Martín-Hernández ${ }^{1}$, S. Agut ${ }^{2}$, J.L. Azkue ${ }^{3}$, M. Gil-Lacruz ${ }^{3}$, A.I. Gil-Lacruz ${ }^{4}$ \\ ${ }^{1}$ Facultad de Ciencias Sociales y Humanas, Universidad de Zaragoza (SPAIN) \\ ${ }^{2}$ Facultad de Ciencias de la Salud, Universitat Jaume I (SPAIN) \\ ${ }^{3}$ Facultad de Ciencias de la Salud, Universidad de Zaragoza (SPAIN) \\ ${ }^{4}$ Escuela de Ingeniería y Arquitectura, Universidad de Zaragoza (SPAIN)
}

\begin{abstract}
Regardless of their form, educational games have as primary purpose educating or training. In the higher university context, serious games, gamification and game-based learning, are designed to make educational processes more efficient. A growing body of research has shown that the incorporation of games in the classroom is often more effective than traditional teaching methods in terms of active participation, concentration, development of social and solving problems skills, academic achievements and performance among university students. Furthermore, games can enhance intrinsic motivation, flow experiences, and engagement, as well as some relevant key groups' skills as teamworking. In order words, learning would be interesting, motivating, engaging, funny and effective through games.
\end{abstract}

However, a substantial part of the aforementioned results regard to usefulness and relevance of game based learning, come from digital games. In this sense, it has been noted that digital game environments cannot provide face-to-face interaction, while in a classroom situation, student-student interactions could exert a profound impact on learning. Game based learning based on this face-toface interaction could be even more crucial in the case of Psychology undergraduates. As future psychologists, they will often have to work, on the basis of that face-to-face interaction, managing groups and work teams that will have to be effective. An important part of key knowledges to develop such competence must be learned in the classroom of Groups Psychology, at the end of the third course of Psychology Degree.

In this context, the main objective of this work is to evaluate the effects of a group simulation gamebased learning experience, in terms of intrinsic motivation, engagement and teamworking amongst psychology undergraduates. Such game-based learning experience implies for the undergraduates to use some of the learnings and knowledges related to the physical and social environment of the groups that will be easier acquired and interiorized through this game. Psychology undergraduates are confronted in small groups -around five members- to a new and a potential stressing situation that needs a fast and effective solution. Our results, in a sample composed by the 31 Psychology Undergraduates that participated in the game, based on face-to-face interaction, showed that after it, undergraduates' intrinsic motivation was higher, as well as, they experienced more engagement, and a stronger sense of team building within their own work group. We think these findings are useful in order to foster intrinsic motivation, engagement, and team working among university students.

Keywords: Motivation, engagement, team building, psychology undergraduates, game-based learning.

\section{INTRODUCTION}

Gamification has been generally defined as the application of gameful thinking and game mechanics in non-game contexts to engage users in solving problems or carrying out tasks [1]. There is a wide variety of forms of using games in non-game contexts, as working and educational ones (e.g. the use of narratives in order to change the context around a typical activity, the creation of social competition) [2]. Regardless of their form, educational games have as primary purpose educating or training [3]. In the higher university context, serious games, gamification and game-based learning, are designed to make educational processes more efficient. Due to its potential in terms of learning and training a wide array of knowledges, core competences, attitudes, and skills though an enjoying and motivating way, it has been affirmed that gamification represents a powerful tool to transform Higher Education as well [2]. It is interesting to note that when gamification adopts the form of a simulation game convey course 
material actively rather than passively levels of declarative and procedural knowledge as well retention for trainees taught are higher, building more confidence for on-the-job application of learned knowledge than classroom instruction does [4][5].

In this sense a still limited [2], but growing body of research has shown that the incorporation of games in the classroom is often more effective than traditional teaching methods, in terms of active participation, concentration, development of social and solving problems skills, and academic achievements and performance among university students [6][7][8][9]. Furthermore, games can enhance intrinsic motivation [7][8] flow experiences, and engagement [10][11][12][13], as well as some relevant key groups' skills as teamworking [14]. In order words, learning would be interesting, motivating, engaging, funny and effective through games.

However, a substantial part of the aforementioned results regard to usefulness and relevance of game based learning, come from digital games. In this sense, it has been noted that digital game environments cannot provide face-to-face interaction, while in a classroom situation, student-student interactions could exert a profound impact on learning [15]. Game based learning based on this faceto-face interaction could be even more crucial, in the case of Psychology undergraduates. As future psychologists, they will often have to work through face-to-face interaction, managing groups and working in teams in an effective way. An important part of key knowledge to develop such competence must be learned in the subject of Groups Psychology, at the end of the third course of Psychology Degree. The list of important topics to learn and work in this subject is extensive, but among all of them the so-called effects of the physical, social and personal environment on group dynamics and performance are especially relevant [16].

In this context, the main objective of this work is to evaluate the effects of a group simulation gamebased learning experience in terms of intrinsic motivation, engagement and teamworking amongst psychology undergraduates. Such game-based learning experience implies for the undergraduates to use the acquired knowledge related to the physical and social environment of the groups that will be easier acquired and developed through this game. Psychology undergraduates are confronted in small groups -around five members- to a new and a potential stressing situation that needs a fast and effective solution.

\section{METHODOLOGY}

\subsection{Participants}

A total of 31 Psychology undergraduate students participated in the game $(48 \%$ of the total of those enrolled in the subject Group Psychology). They were randomly assigned to this game condition on the basis of alphabetical order by last name. Before and after the game participants completed the instrument used to measure the researched variables. Written consent was obtained as a previous step. Participants' age ranged from 20 to 24 years old $(M=20.7 ; S D=.88)$. Of them, $87.1 \%$ were women.

\subsection{Measures}

Motivation was measured using a validated Spanish version of the Academic Motivation Scale (AMS) [17]. This 28 items instrument captures intrinsic, as well as, extrinsic motivation asking the undergraduates about the reasons that have led them to learn at the university. For our research purpose we used the 12 items related to intrinsic motivation ranged on a 6-point Likert scale from 1 (completely disagree) to 6 (completely agree). A sample item is "Because I enjoy learning new things". Cronbach's $\alpha$ were 0.89 before playing the game (T1) and 0.91 after played it (T2).

Engagement was assessed through an 18 items instrument: The Spanish version of the Utrecht Work Engagement Scale (UWES) [18] adapted to teams [19]. Responses were coded using a 7-point Likert scale from 1 (Never) to 6 (Always). A sample item is "We get carried away by work". Cronbach's $\alpha$ were 0.88 before playing the game (T1) and 0.93 after played it (T2).

Team building was measured using a 12 items instrument, which captures individuals' perceptions in regard sense of teamworking inside his or her group. Items were ranged on a 6-point Likert scale from 1 (completely disagree) to 6 (completely agree). A sample items is "I am going to spend more time with my team members after work". Cronbach's $\alpha$ were 0.90 before playing the game (T1) and 0.94 after played it (T2). 


\subsection{Procedure}

Firstly, we designed and wrote the game, which the teams had to play. Six teams were composed of around five members. These teams had a maximum of 45 minutes to complete the game based on interaction face-to-face in the classroom. Before and after playing the game, participants completed the instrument we used to measure the variables. We named this simulation game as "the group to the rescue". The game included a scenario consisted of travelling through space in a small spaceship (the Chachigate I) for a round trip of two months at least, along with an indeterminate stay in a newly discovered planet (Tesaltion) with an atmosphere such as terrestrial but with a very cold climate, large animals (including dinosaurs), and an exotic vegetation. Players have to use what they learned about the effects of the physical, social and personal environment on group dynamics and performance to conform the group that will have to travel to Tesaltion. The formed group will have to explore it, and to indicate on the basis of the information they gather during their stay there, if it is possible for the humanity to live in, because the Earth is disappearing. Every team of players has to form such group from twelve possible characters that varied in age, gender, ethnicity, abilities, personality traits, intelligence and attitudes. The prize for all groups and players is neither them, nor their families, nor their loved ones and friends will suffer any damage: They will have a preferred place in the big spaceship CHACHIGATE II, when it is built. The first group that completed the report will have a V.I.P. place in the spaceship. Every group had to provide a report signing all the elected members to conform the group that will explore Tesaltion in the order in which she or he was incorporated into the group, explaining the main reasons taken into account to shape such group.

\section{RESULTS}

\subsection{Motivation t-test and results}

Significant differences between the mean scores in T1 (before playing the game) and time T2 (after playing the game) in terms of intrinsic motivation were obtained. As can be seen in Table 1 the followup paired t-test indicated that playing the game produced an enhancement on Psychology undergraduates' intrinsic motivation $(\mathrm{t}(30)=-2.191 ; p<.05)$, being higher in time 2 (MeanT1= 5.05, MeanT2= 5.16).

Table 1. T-test: Intrinsic Motivation.

\begin{tabular}{|c|c|c|c|c|c|c|c|}
\hline & Time & $\mathrm{N}$ & Mean & SD & \multicolumn{3}{|c|}{ T-test } \\
\hline & & & & & $t$ & $d f$ & $p$ \\
\hline \multirow{2}{*}{$\begin{array}{l}\text { Intrinsic } \\
\text { Motivation }\end{array}$} & 1 & 31 & 5.05 & 0.61 & -2.191 & 30 & $0.036^{*}$ \\
\hline & 2 & 31 & 5.16 & 0.60 & & & \\
\hline
\end{tabular}

\subsection{Engagement t-test analysis and results}

We found significant differences between the mean scores in T1 (before playing the game) and time T2 (after playing the game) in terms of group engagement. As can be seen in Table 1 the follow-up paired t-test indicated that playing the game produced an enhancement of group engagement perceptions $(\mathrm{t}(30)=-2.833 ; p<.01)$, being higher in time $2($ MeanT1 $=4.75$, MeanT2= 5.12).

Table 2. T-test: Group Engagement.

\begin{tabular}{l|c|c|c|c|c|c|c}
\hline \hline & Time & $\mathrm{N}$ & Mean & SD & \multicolumn{3}{c}{ T-test } \\
\hline Group & 1 & 31 & 4.75 & 0.73 & -2.833 & 30 & $0.008^{* *}$ \\
Engagement & 2 & 31 & 5.12 & 0.90 & & & \\
\hline \hline
\end{tabular}

$$
\text { ** } p<.01
$$




\subsection{Engagement t-test analysis and results}

As can be seen in Table 3 significant differences between the mean scores in T1 (before playing the game) and time T2 (after playing the game) in terms of team building were obtained. The follow-up paired t-test indicated that playing the game produced an enhancement of perceptions of team building of own team work $(\mathrm{t}(30)=-3.939 ; \mathrm{p}<.001)$, being higher in time $2($ MeanT1 $=4.90$, MeanT2= 5.24).

Table 3. T-test: Team building.

\begin{tabular}{|c|c|c|c|c|c|c|c|}
\hline & Time & $\mathrm{N}$ & Mean & SD & \multicolumn{3}{|c|}{ T-test } \\
\hline & & & & & $t$ & df & $p$ \\
\hline \multirow{2}{*}{$\begin{array}{l}\text { Team } \\
\text { building }\end{array}$} & 1 & 31 & 4.90 & 0.51 & \multirow[t]{2}{*}{-3.939} & \multirow[t]{2}{*}{30} & \multirow{2}{*}{$0.000^{* * *}$} \\
\hline & 2 & 31 & 5.24 & 0.66 & & & \\
\hline
\end{tabular}

$* * * 0<.01$

\section{CONCLUSIONS}

This paper dealt with the estimation of the effects of a group simulation game-based learning experience in terms of intrinsic motivation, engagement and teamworking amongst Psychology undergraduates. Such game-based learning experience implied for the undergraduates to use the acquired knowledge related to the physical and social environment of the groups that will be easier acquired and interiorized through this game. Psychology undergraduates were confronted in small groups -around five members- to a new and a potential stressing situation that needed a fast and effective solution. Our results, showed that after playing it, undergraduates intrinsic motivation was higher, as well as, they experienced more engagement, and a stronger sense of team working -or in other words team building- within their own work group. This results agree with previous empirical evidence that support the positive influence that game based learning exert on intrinsic motivation, engagement and team working [6][7][8][9][10][11][12][13]. Moreover, we think such results are useful in order to foster such key aspects, especially if we take into account that the developed and used game was played face-to-face.

This study is not exempt from limitations, as for example the higher number of female participants, compared to male peers, as well as, the fact that we did not use a control group. However, no significant differences appear in previous research regard to the relationship between gender and game based-learning. Future studies including higher number of male participants, as well as, a control group, should be developed, in order to generalize results obtained in this study. As well, this study could be carried out with samples of high school students. Statistics reveal that the school failure rate is higher than is desirable in this educational stage.

In conclusion, the findings highlight the potential of tasks that involve gaming to contribute to the enhancement of intrinsic motivation, engagement and team building, which are so essential in educational context, as well as, future professional development as psychologist. As an example, It is well established that intrinsic motivation exerts a key and crucial influence on a wide arrange of learning outcomes, as achievement, satisfaction, and performance expectations [20][15]. More research is needed to fully examine games based learning effects and determine how to achieve the best sustained intrinsic motivation, engagement and team building. The findings of this research would have important educational implications which could be transferred to any educational stage, since the most initial to the highest levels.

\section{ACKNOWLEDGEMENTS}

This study had been possible thanks to the teaching innovation project "La gamificación como herramienta de fomento del aprendizaje activo y la construcción de equipo (Team Building)" PIIDUZ_17_159, Vicerrectorado de Política Académica, Universidad de Zaragoza. We also want to express our gratitude to the Department of Psychology and Sociology of the University of Zaragoza and to all the participants in this study. 


\section{REFERENCES}

[1] S. Deterding, M. Sicart, L. Nacke, K. O'Hara, \& D., Dixon, "Gamification: using game-design elements in non-gaming contexts", In Proceedings of the 2011 Annual Conference on Human Factors in Computing Systems, pp. 2425-2428, 2011.

[2] M. D. Hanus, \& J. Fox, "Assessing the effects of gamification in the classroom: A longitudinal study on intrinsic motivation, social comparison, satisfaction, effort, and academic performance", Computers \& Education, vol. 80, pp. 152-160, 2015.

[3] J. Hamari, D. J. Shernoff, E. Rowe, B. Coller, J. Asbell-Clarke, \& T. Edwards, "Challenging games help students learn: An empirical study on engagement, flow and immersion in gamebased learning", Computers in Human Behavior, vol. 54, January, pp. 170-179, 2016.

[4] T. Sitzmann, "A meta-analytic examination of the instructional effectiveness of computer-based simulation games", Personnel Psychology, vol. 64, no 2, pp. 489-528, 2011.

[5] M. Sailer, J. Hense, H. Mandl, \& M. Klevers, "Fostering development of work competencies and motivation via gamification" in Competence-based Vocational and Professional Education (M. Mulder ed.), pp. 795-818. Cham: Springer, 2017.

[6] A. losup, \& D. Epema, "An experience report on using gamification in technical higher education", in Proceedings of the 45th ACM technical symposium on Computer science education, pp. 27-32, 2014.

[7] A. Domínguez, J. Saenz-de-Navarrete, L. De-Marcos, L. Fernández-Sanz, C. Pagés, \& J. J. Martínez-Herráiz, "Gamifying learning experiences: Practical implications and outcomes", Computers \& Education, vol. 63, pp. 380-392, 2013.

[8] D., Dicheva, C. Dichev, G. Agre, \& G. Angelova, "Gamification in education: A systematic mapping study", Journal of Educational Technology \& Society, vol. 18, no. 3, pp. 75-88, 2015.

[9] J. Hamari, "Do badges increase user activity? A field experiment on the effects of gamification", Computers in Human Behavior, vol. 71, pp. 469-478, 2017.

[10] F. F. H., Nah, Q. Zeng, V. R. Telaprolu, A. P., Ayyappa, \& B. Eschenbrenner, "Gamification of education: a review of literature", in International conference on $\mathrm{HCl}$ in business (F. F. H. Nah ed.), pp. 401-409. Cham: Springer, 2014.

[11] Z. Fitz-Walter, D. Tjondronegoro, \& P. Wyeth, "Orientation passport: using gamification to engage university students", in Proceedings of the 23rd Australian computer-human interaction conference, pp. 122-125, 2011.

[12] J. Looyestyn, J. Kernot, K. Boshoff, J. Ryan, S. Edney, \& C. Maher, "Does gamification increase engagement with online programs? A systematic review", PloS one, vol 12, no 3, pp. 1-19, 2017. Retrieved from https://doi.org/10.1371/journal.pone.0173403.

[13] L. Ding, E., Er, \& M., Orey, "An exploratory study of student engagement in gamified online discussions", Computers \& Education, vol. 120, pp. 213-226, 2018.

[14] J. M. Beaubien, \& D. P. Baker, "The use of simulation for training teamwork skills in health care: how low can you go?", BMJ Quality \& Safety, vol. 13, suppl. 1, pp. i51-i56, 2004.

[15] E. Z. F. Liu, \& P. K. Chen, "The effect of game-based learning on students' learning performance in science learning-A case of "Conveyance Go", Procedia-Social and Behavioral Sciences, vol. 103, pp. 1044-1051, 2013.

[16] F. Gil \& C. M. Alcover, Introducción a la Psicología de los Grupos. Madrid: Pirámide, 2008.

[17] R. J. Vallerand, M. R. Blais, N. M. Briere, \&, L. G. Pelletier LG, "Construction et validation de I'Echelle de Motivation en Éducation (EME)", Canadian Journal of Behavioral Sciences, vol. 21, pp. 323-349, 1998.

[18] W. B. Schaufeli, M. Salanova, V. González-Romá, \& A. B. Bakker, "The measurement of engagement and burnout: A two sample confirmatory factor analytic approach", Journal of Happiness studies, vol. 3, no. 1, pp. 71-92, 2002. 
[19] M. Salanova, S. Llorens, E. Cifre, I. Martínez, \& W. B. Schaufeli, "Perceived collective efficacy, subjective well-being and task performance among electronic work groups: An experimental study", Small Group Research, vol. 34, no. 1, pp. 43-73, 2003.

[20] R. H. Shroff, \& C. J. Keyes, "A proposed framework to understand the intrinsic motivation factors on university students' behavioral intention to use a mobile application for learning", Journal of Information Technology Education: Research, vol.16, pp. 143-168, 2017. 